\title{
Properties of Silicon Dioxide Amorphous Nanopowder Produced by Pulsed Electron Beam Evaporation
}

\author{
Vladislav G. Il'ves, ${ }^{1,2}$ Michael G. Zuev, ${ }^{2,3}$ and Sergey Yu. Sokovnin ${ }^{1,2}$ \\ ${ }^{1}$ Institute of Electrophysics, Ural Branch of the Russian Academy of Sciences (RAS), Amundsen 106, Yekaterinburg 620016, Russia \\ ${ }^{2}$ Ural Federal University Named after the First President of Russia B. N. Yeltsin, Mira 19, Yekaterinburg 620002, Russia \\ ${ }^{3}$ Institute of Solid State Chemistry, Ural Branch of RAS, Pervomayskaya 101, Yekaterinburg 620049, Russia
}

Correspondence should be addressed to Vladislav G. Il’ves; ilves@iep.uran.ru

Received 24 July 2015; Revised 21 September 2015; Accepted 29 September 2015

Academic Editor: Carlos R. Cabrera

Copyright (C) 2015 Vladislav G. Il'ves et al. This is an open access article distributed under the Creative Commons Attribution License, which permits unrestricted use, distribution, and reproduction in any medium, provided the original work is properly cited.

$\mathrm{SiO}_{2}$ amorphous nanopowder (NP) is produced with the specific surface area of $154 \mathrm{~m}^{2} / \mathrm{g}$ by means of evaporation by a pulsed electron beam aimed at Aerosil 90 pyrogenic amorphous NP $\left(90 \mathrm{~m}^{2} / \mathrm{g}\right)$ as a target. $\mathrm{SiO}_{2}$ NP nanoparticles showed improved magnetic, thermal, and optical properties in comparison to Aerosil 90 NP. Possible reasons of emergence of $\mathrm{d}^{0}$ ferromagnetism at the room temperature in $\mathrm{SiO}_{2}$ amorphous NP are discussed. Photoluminescent and cathode luminescent properties of the $\mathrm{SiO}_{2}$ NP were investigated.

\section{Introduction}

Messages that silicon $[1,2]$ and silicon dioxide $\left(\mathrm{SiO}_{2}\right)[3,4]$ possess noticeable magnetic properties at room temperature appear now in increasing frequency. Besides, porous silicon is widely known for the bright white luminescence $[5,6]$, and amorphous nanostructures (nanowires, nanoedges, nanotubes, etc.) from silicon dioxide emit intensive blue light $[7,8]$. Researches of magnetic and luminescent properties at $\mathrm{Si} / \mathrm{SiO}_{2}[9-13]$ interface are actively conducted.

In particular, an actual task is the creation of a luminescent light source on the basis of one material in which luminescence spectra contain bands where total radiation gives white luminescence [14].

Inexpensive, with small content of chemical impurities, $\mathrm{SiO}_{2}$ pyrogenic nanopowders (NPs) (commercial name: Aerosil, by Degussa company) are convenient for production of an evaporated target in gas-phase methods for producing powders (laser ablation, thermal evaporation, magnetron sputtering, etc.), in particular, at pulsed electron beam evaporation [15].

Magnetic and optical properties of silicon and its compounds indicate possibility of simultaneous production of new modified magnetic-luminescent materials on the basis of $\mathrm{Si}-\mathrm{SiO}_{2}$ system in powder or thin film form, in amorphous, crystalline, or mixed amorphous-nanocrystalline states with improved parameters. Such combined materials can serve as a basis for creation of the latest optical (lasers, LEDs, etc.) and spintronic devices $[16,17]$.

The purpose of this work consisted in producing $\mathrm{SiO}_{2}$ nanopowder by target evaporation from Aerosil 90 NP in vacuum by means of the pulsed electron beam and investigation of main properties of the nanopowder produced.

\section{Experimental}

$\mathrm{SiO}_{2}$ amorphous nanopowder has been produced on NANOBIM-2 [15] installation by pulsed electron evaporation in vacuum (residual pressure: $4 \mathrm{~Pa}$ ). NP was deposited on large-surface glass noncooled substrates located around the target at the distance of $10-15 \mathrm{~cm}$.

The target was made of Aerosil 90 NP [18] which was preannealed for 2 hours at temperature of $1100^{\circ} \mathrm{C}$ to improve pressing of the target from the annealed powder by means of manual press.

Mode of the target evaporation was as follows: accelerating voltage: $37 \mathrm{kV}$, beam current: $0.5 \mathrm{~A}$, pulse duration: 
$100 \mu \mathrm{s}$, pulse repetition rate: $100 \mathrm{~Hz}$, target rotation speed: 2.5 turns/min, and evaporation time: $20 \mathrm{~min}$. NP collection from glasses was $0.3 \mathrm{~g}$. Produced NP differed from the friable and fluffy Aerosil powder considerably. Upon removal from the glass surface by means of titanic foil, the powder coagulated in rolls, while certain portions of the coating were rolling down in rolls spontaneously in the course of deposition. NP appearance indicated its fibrous texture.

The following diagnostics were used for analysis of NP properties: powder X-ray diffraction (XRD) was made on XRD 7000 diffractometer; the powder specific surface area $\left(\mathrm{S}_{\text {ssa }}\right)$ was defined by Brunauer-Emmett-Teller (BET) method on Micromeritics TriStar 3000 installation; magnetic characteristics were defined on Cryogenic CFS-9T-CVTI vibration magnetometer at $300 \mathrm{~K}$. Thermograms of heating/cooling and mass spectrums were recorded by means of differential scanning calorimetry (DSC) and thermogravimetric (TG) measurements methods on STA-409-PC Luxx synchronous thermoanalyzer combined with QMS-403C mass spectrometer by NETZSCH, in the temperature range $40-1400^{\circ} \mathrm{C}$.

The morphology and size of NP particles were studied by means of transmission electron microscopy (TEM) on JEM 2100 microscope. Concentration of impurity iron in $\mathrm{SiO}_{2}$ was determined by methods of energy-dispersive X-ray (EDX) spectroscopy on TEM and mass spectrometry with inductively coupled plasma (ICP) on ELAN 9000 spectrometer. Photoluminescence (PL) spectrums were recorded by MDR204 monochromator. Infrared (IR) absorption spectrums were recorded by Spectrum one device by Perkin-Elmer from powders suspended in vaseline oil in the frequency range from 400 to $1000 \mathrm{~cm}^{-1}$. The pulsed cathodoluminescence (PCL) was investigated with KLAVI_1 setup.

\section{Results and Discussion}

According to BET analysis, $\mathrm{S}_{\text {ssa }}$ of $\mathrm{SiO}_{2} \mathrm{NP}$ was $154 \mathrm{~m}^{2} / \mathrm{g}\left(\mathrm{S}_{\text {ssa }}\right.$ of Aerosil NP is equal to $90 \mathrm{~m}^{2} / \mathrm{g}$, according to the producer's data [18]).

The microscopic analysis of Aerosil and $\mathrm{SiO}_{2}$ NPs was made with purpose of comparison. TEM pictures of studied NPs are given in Figure 1; the illustration allows seeing well the distinction in porosity and sintering behaviour of the compared powders. Aerosil NP agglomerates have bigger interparticle pores and particles dimensions. The form of Aerosil particles (Figure 1(a)) is close to spherical; the surface of particles is smooth and does not contain pores. Diameter of the produced $\mathrm{SiO}_{2}$ particles is approximately twice smaller than that of Aerosil particles $(20 \mathrm{~nm})$. The form of the produced $\mathrm{SiO}_{2}$ particles is far from spherical (Figure 1(b)), and the surface of particles is rough.

Particles of $\mathrm{SiO}_{2}$ NP (Figure 1(d)) are sintered much stronger than particles of Aerosil (Figure 1(b)). It is an important factor that indicates emergence of ferromagnetic properties $\left(\mathrm{d}^{0}\right.$ ferromagnetism [20]) in pure diamagnetics and $\mathrm{SiO}_{2}$ in particular.

The data of the X-ray phase analysis (Figure 2) and the electron diffraction analysis (insert in Figure 1(d)) confirmed the amorphous condition of $\mathrm{SiO}_{2} \mathrm{NP}$ and absence of secondary magnetic phases therein in the form of pure iron and its oxides.

The XRD patterns of $\mathrm{SiO}_{2} \mathrm{NP}$ before and after annealing sample at temperature of $1000^{\circ} \mathrm{C}$ in the air atmosphere are shown in Figure 2.

The sample before annealing is completely amorphous (no Bragg peaks). In the annealed sample, the crystalline phases of $\mathrm{SiO}_{2}$ of three structural modifications are found: quartz (PDF 00-046-1045), cristobalite (PDF 00-039-1425), and crystalline structure of $\mathrm{SiO}_{2}$, prepared by the sol-gel method (PDF 01-075-3159, [19]). The crystallinity degree of the annealed sample, as calculated in the XRD Crystallinity program, was $17 \%$.

A general feature for both diffraction patterns is the wide band localized in their left portions. However, the top of the band is shifted after annealing ( $\Delta \theta$-shift of the band top) to lower values of diffraction angles, from 24 to almost 22 degrees (Figure 2). It is worth noting that cristobalite possesses the main peak of diffraction at $\approx 22^{\circ}$, and many authors noted correlation of the wide band shift $\Delta \theta$, induced by heat treatment, with structural conformational changes in the silica grid [19].

By means of thermal analysis, it is established that, at dynamic heating of samples with the speed of $100^{\circ} \mathrm{C} / \mathrm{min}$, the produced $\mathrm{SiO}_{2} \mathrm{NP}$ starts to crystallize at temperature about $1050^{\circ} \mathrm{C}$ (see endothermic peak in Figure 4(a)) and stops crystallizing at temperature about $1280^{\circ} \mathrm{C}$. Please note that on Aerosil thermogram (Figure 3(b)) the corresponding exothermic peak from crystallization of the amorphous phase is hardly noticeable.

Partial crystallization of Aerosil NP amorphous phase at dynamic heating is indicated by the insignificant deviation of the baseline of DSC curve at temperature about $1250^{\circ} \mathrm{C}$ (Figure 3(b)), whereas all parameters of the exothermic peak (temperature of beginning/completion of amorphous phase crystallization, the exothermic peak maximum) are displaced towards high temperatures approximately by $200^{\circ} \mathrm{C}$, in comparison with the corresponding parameters of the produced $\mathrm{SiO}_{2} \mathrm{NP}$.

Therefore, during dynamic heating at the rate of $10^{\circ} \mathrm{C} /$ min, there is no sufficient time for crystallization of Aerosil. The reason of distinction in temperatures of crystallization beginning in the amorphous powders under study is related to their morphology. As it was noted above, the produced particles of $\mathrm{SiO}_{2}$ possess more developed rough surface (Figure 1(c)), in comparison to the smooth surface of Aerosil's spherical particles (Figure 1(a)), which contributes to the decrease of their crystallization temperature in the amorphous phase and, respectively, of sintering temperature. The big specific surface area and low sintering temperature of $\mathrm{SiO}_{2} \mathrm{NP}$ are favourable for its use in catalysis, ceramic synthesis, dentistry, and other areas.

Weight decrease during $\mathrm{SiO}_{2} \mathrm{NP}$ heating up to $800^{\circ} \mathrm{C}$ (9.25 wt.\%) exceeds the respective loss of mass of Aerosil NP almost twice (see TG and water mass spectrums curves in Figures 3(a) and 3(b)), which indicates the increased hydrophility of the produced NP. 


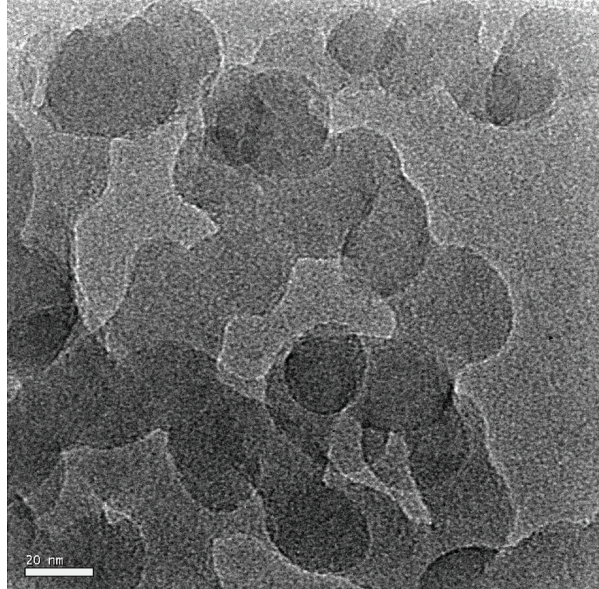

(a)

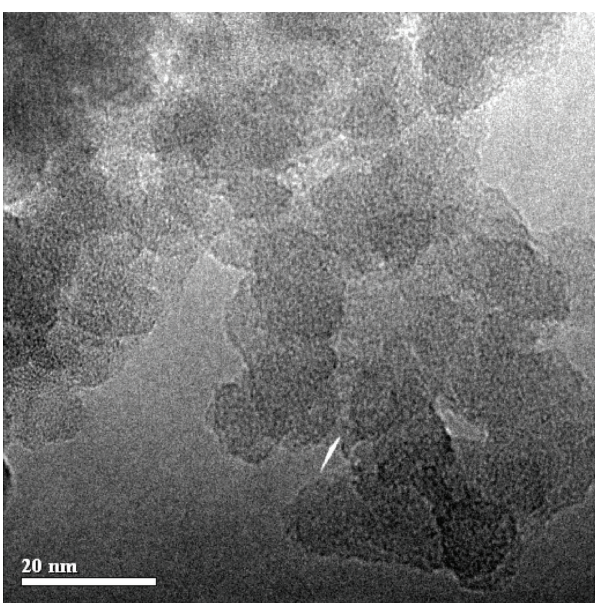

(c)

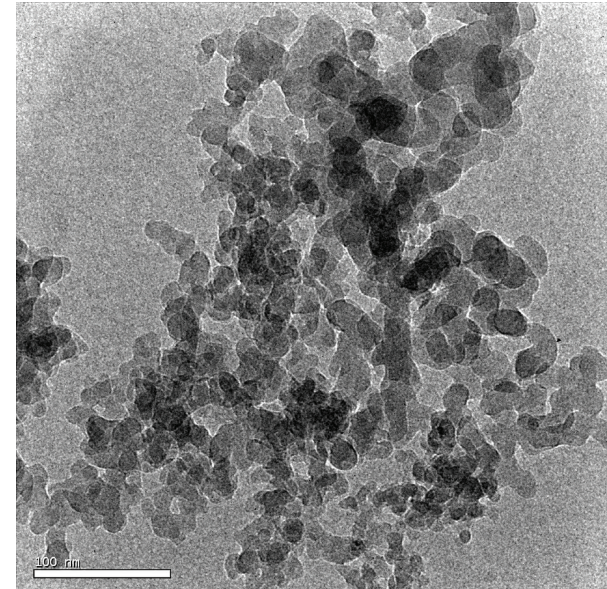

(b)

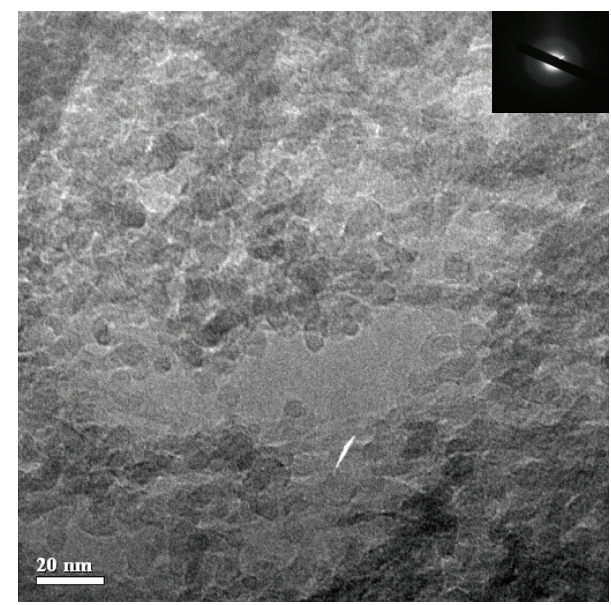

(d)

Figure 1: (a, b) TEM pictures of Aerosil $90 \mathrm{NP}$ and (c, d) of $\mathrm{SiO}_{2} \mathrm{NP}$, produced with various magnifications. On the insert of (d), see the electron diffraction pattern from the amorphous area of the sample.

According to magnetic measurements, it is established that Aerosil NP shows typical diamagnetic behavior (Figure 4(a)), while $\mathrm{SiO}_{2} \mathrm{NP}$ shows ferromagnetic behavior at room temperature (Figure 4(b)). The magnetization curve of $\mathrm{SiO}_{2} \mathrm{NP}$ is anhysteretic, which is characteristic for $\mathrm{d}^{0}$ ferromagnetics, both pure and doped with nonmagnetic elements $[20,21]$. The saturation magnetization of $\mathrm{SiO}_{2} \mathrm{NP}$ was $0.25 \mathrm{emu} / \mathrm{g}$; the coercive force and residual magnetization are close to zero within the measurement error. Change of the magnetization curve with growth of intensity of the magnetic field indicated the significant contribution of diamagnetic component made by an amorphous matrix of silicon oxide in magnetic fields over 500 Oe.

The chemical analysis of $\mathrm{NP} \mathrm{SiO}_{2}$ made by the ICP and EDX methods showed that concentration of impurity iron does not exceed $(7.4) * 10^{-2}$ and $(1-3) * 10^{-2} \mathrm{wt} . \%$, respectively.

The calculated magnetic response from impurity iron $(220 \mathrm{emu} / \mathrm{g})$ is almost twice less than the measured one, which excludes the impurity nature of the magnetism observed.
The aforesaid is confirmed by results of work [22] where the maximum magnetization of saturation nanocomposite films $\mathrm{Fe}_{2} \mathrm{O}_{3} / \mathrm{SiO}_{2}$ was 10 times less $\left(2.125 * 10^{-2} \mathrm{emu} / \mathrm{g}\right)$ at concentration of $\mathrm{Fe}_{2} \mathrm{O}_{3}$ (30\% wt.) 300 times higher than in our sample $\mathrm{SiO}_{2}$.

Specified in Figure 5 are IR spectra of amorphous Aerosil silicon oxides and produced $\mathrm{SiO}_{2}$ NP. A sample of $\mathrm{SiO}_{2} \mathrm{NP}$ demonstrated the shift of frequencies in the smaller values area (Table 1). This shift could indicate some extent reduction of polymerization of silicon and disordering of its amorphous structure in the course of $\mathrm{SiO}_{2}$ evaporation [23]. Emergence of $\nu \mathrm{OH}$ and $\nu(\mathrm{Si}-\mathrm{OH})$ in the range of frequencies is caused by capture of water vapours by amorphous NP of silicon oxide.

Room temperature PCL spectra of $\mathrm{SiO}_{2} \mathrm{NP}$ are shown in Figure 6 . The spectra overlap practically all visible range of waves lengths. Values of the peaks centers are presented in Table 2 in the range obtained at Gaussian decomposition of bands by means of the program ORIGIN.

Characteristic of the range is existence of a relatively narrow intensive band at $618 \mathrm{~nm}$. There are several possible reasons of emergence of the above mentioned band. 


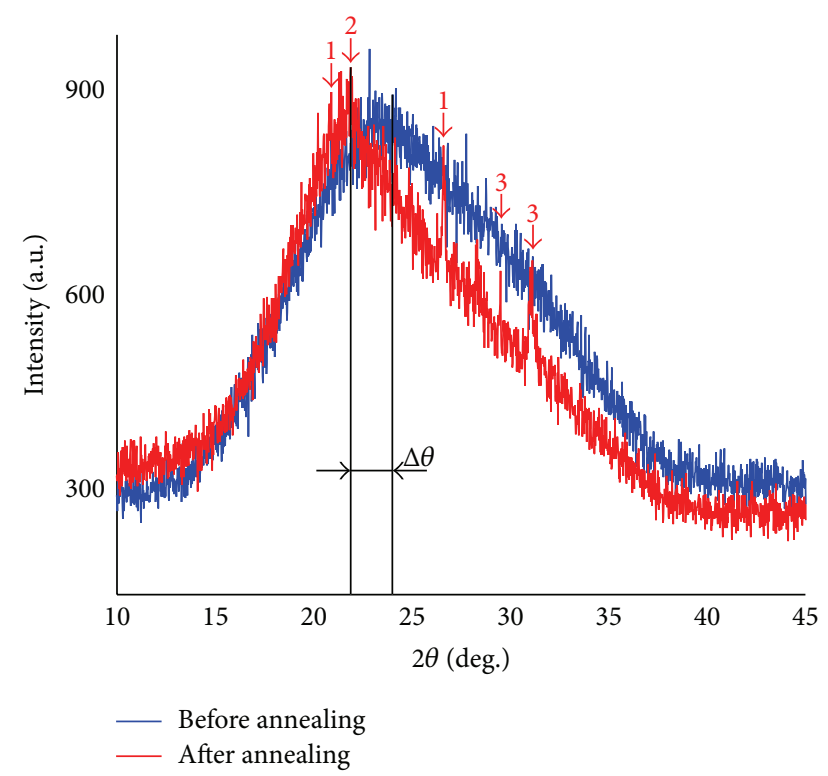

FIgURE 2: XRD patterns of $\mathrm{SiO}_{2} \mathrm{NP}$ before and after annealing at temperature of $1000^{\circ} \mathrm{C}$ within 24 hours. Peaks designated by arrows: 1, quartz; 2, cristobalite; 3, crystalline structure of $\mathrm{SiO}_{2}$ [19].

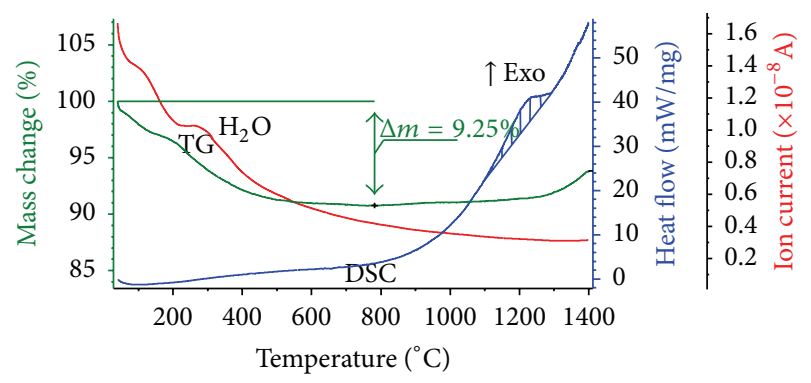

(a)

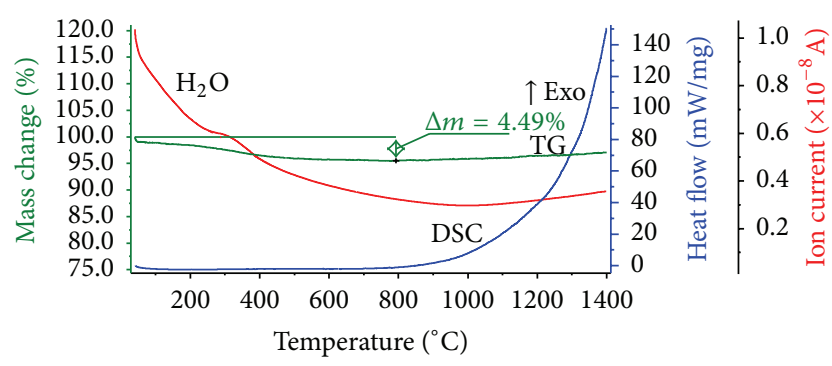

(b)

FIGURE 3: Heating curves of DSC-TG and $\mathrm{H}_{2} \mathrm{O}$ mass spectrums in the temperature interval of $40-1400^{\circ} \mathrm{C}$ : (a) amorphous $\mathrm{SiO}_{2} \mathrm{NP}$ and (b) amorphous Aerosil 90 NP.

The cathodoluminescence spectra in Figure 6 consist of 9 partially overlapping bands: (i) one band in the blue region at about $451.5 \mathrm{~nm}$ arising from oxygen deficiency-related centers (ODC) or twofold-coordinated silicon centers ( $\equiv \mathrm{Si}-\mathrm{S} \equiv)$, which are generated in the presence of oxygen vacancy sites; (ii) one band in the green region at around $513 \mathrm{~nm}$ which can be connected with deficiency of oxygen (oxygen vacancies), or the autolocalized excitons (self-trapped exciton); (iii) one yellow band at about $590 \mathrm{~nm}$ connected with the hole centers on the nonbridging oxygen atoms (nonbridging oxygen hole center- $\mathrm{NBOHC}$ ) and with the presence of the $\mathrm{OH}$ group; (iv) and series from 6 red bands in the energy range 1.56$2.0 \mathrm{eV}$, mostly connected with silicon nanoclusters.

Rather weak band with a maximum at $1.91 \mathrm{eV}$ (number 5 in Figure 6) with a high probability is connected with the radiation of nonbridging oxygen atom which is considered one of the most well studied point defects in glass [24].

The luminescence of the other four red bands (numbers 6-9 in Figure 6) is most possibly connected with existence of silicon nanoclusters in the received $\mathrm{SiO}_{2} \mathrm{NP}$ [25].

Silicon nanoclusters could appear in $\mathrm{SiO}_{2} \mathrm{NP}$ as a result of two processes: the dissociation of silicon dioxide vapors and the inverse diffusion of silicon atoms from the glass substrate in the deposited NP, especially in its primary layers. In Zamoryanskaya's works [24, 26-29], it is shown that direct impact of an electron beam on silicon dioxide leads to formation of silicon nanoclusters in it. However, in this method of receiving nanoparticles, direct influence of primary electrons after NP deposition on a substrate is excluded; however, they can form by target evaporation. Nevertheless, characteristic bands of luminescence from silicon nanoclusters in the energy range from 1.4 to $1.8 \mathrm{eV}$ [25] are present in the range of Figure 6. Four peaks on cathodoluminescence spectra (numbers 6-9) in the energy range from 1.56 to $1.81 \mathrm{eV}$ confirm existence of Si nanoclusters in the received NP.

Peak number 7 has the largest area. Correlation of silicon nanoclusters average diameter and the energy of photoluminescent peak [30] shows that the $1.76 \mathrm{eV}$ energy matches silicon nanoclusters with the diameter of $4 \mathrm{~nm}$. On TEM picture (Figure 1(d)), the separate and sintered $\mathrm{SiO}_{2}$ nanoparticles with the diameter from 4 to $5 \mathrm{~nm}$ and less are well visible (shown by arrow) which confirms communication of the cathodoluminescent peaks numbers 6-9 with silicon nanoclusters of small size, less than $5 \mathrm{~nm}$.

Extensive amorphous halo and lack of concentric rings on the diffraction pattern of a sample (insert in Figure 1(d)) confirm that silicon nanoparticles and $\mathrm{SiO}_{2}$ in the received $\mathrm{SiO}_{2} \mathrm{NP}$ were in an amorphous state.

The main feature of cathodoluminescence spectra is existence of a narrow intensive band at $618 \mathrm{~nm}$ (peak number 4 in Figure 6). We will give the possible causes for emergence of this band. Here are the possible causes of this band:

(1) At the sample of $\mathrm{SiO}_{2} \mathrm{NP}$, there is an insignificant impurity of $\mathrm{Fe}$ ions $(1-7.4) * 10^{-2} \mathrm{wt} . \%$. Therefore, the band at $618 \mathrm{~nm}$ can allegedly be carried to the luminescence $\mathrm{Fe}^{3+}$ ions (transition $4 \mathrm{G} \rightarrow 6 \mathrm{~S}$ [31]). In [32], in minerals, the luminescence band from $\mathrm{Fe}^{3+}$ ions usually located in the range from 640 to $820 \mathrm{~nm}$ with maximum $730 \mathrm{~nm}$ (e.g., in quartz).

(2) From the evolution of the cathodoluminescence spectrum of pure silica, it is known [30] that the relative intensity of the red band significantly increases and its full width at half-maximum (fwhm) decreases with increasing acceleration voltage; thus, tops of red and blue bands peaks seek to separate from each other 


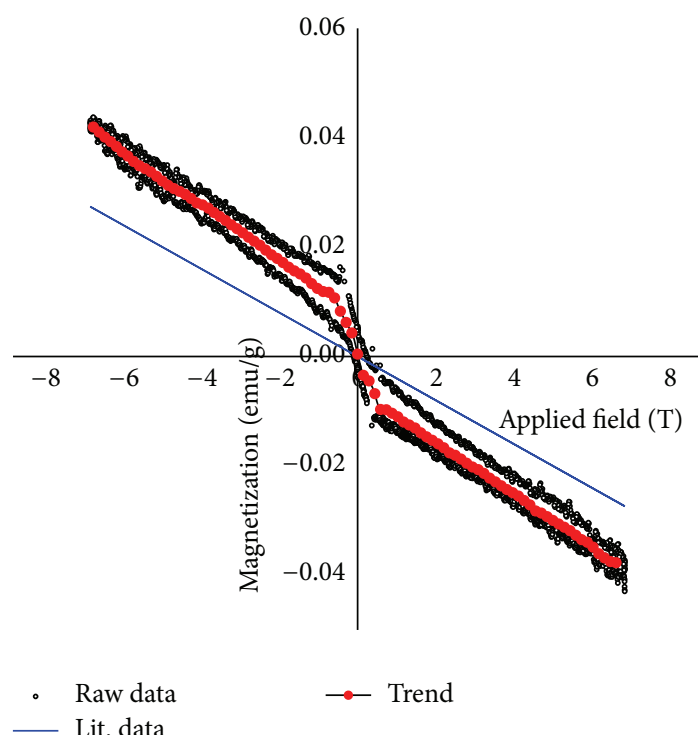

(a)

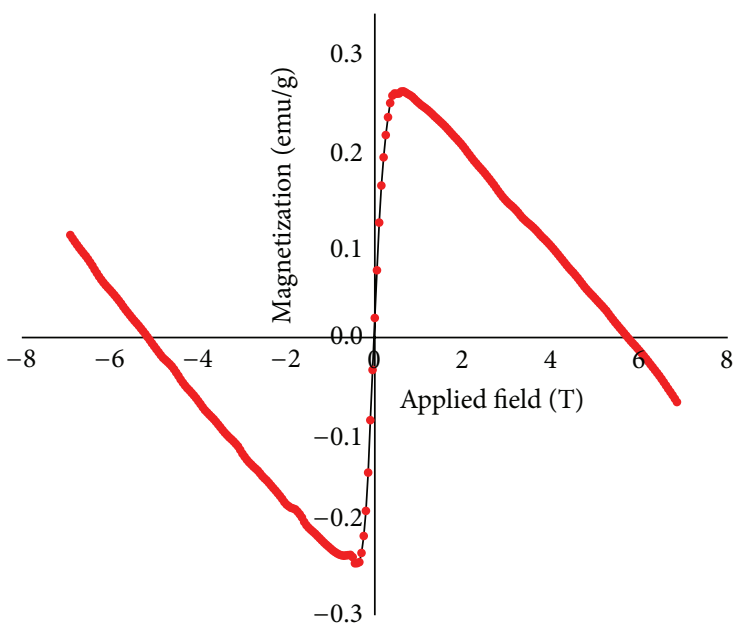

(b)

Figure 4: (a) Field dependent magnetization of Aerosil 90 NP in magnetic field \pm 7 T. (b) Anhysteretic magnetization curve of undoped $\mathrm{SiO}_{2} \mathrm{NP}$ in magnetic field $\pm 7 \mathrm{~T}$.

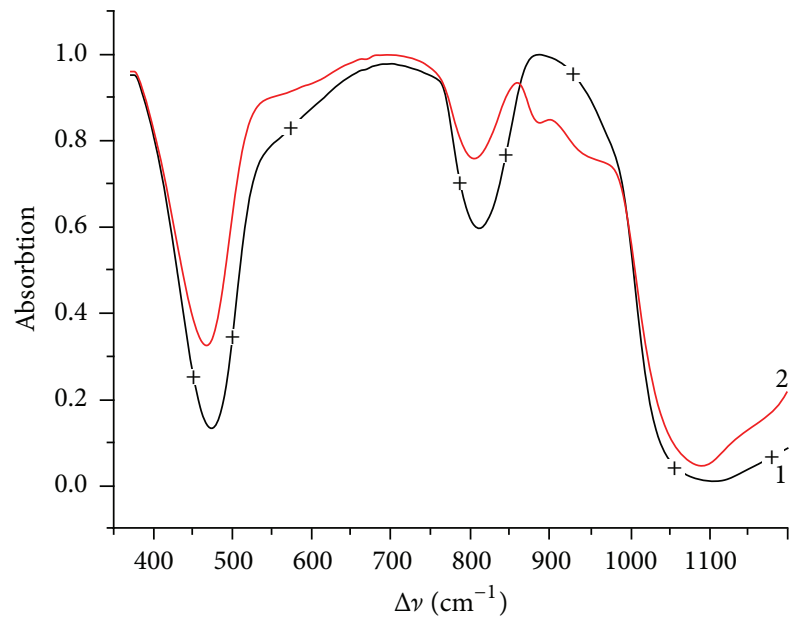

FIGURE 5: IR spectra of silicon oxides (1: Aerosil, 2: $\left.\mathrm{SiO}_{2} \mathrm{NP}\right)$.

with growth energy of electrons (energy of electrons in the KLAVI 1 installation $(180 \mathrm{keV})$ is 10 times bigger than that of electrons $(15 \mathrm{keV})$ from [30]). It is very probable that emergence of narrow intensive peak at $620 \mathrm{~nm}$ is caused by the above circumstance. The feature of cathodoluminescence range of silicon glass [30] reduction of ultraviolet band intensity (up to the total disappearance) during increase of accelerating voltage is confirmed by lack of peak in UV band (Figure 6).

(3) Emergence of a band at $618 \mathrm{~nm}$ can be connected with the presence of nanodimensional silicon at the received powder.

In the literature, the nature of a spectral band in the energy range from 2.0 to $2.2 \mathrm{eV}$ is explained even more widely.
TABLE 1: Frequencies $\left(\mathrm{cm}^{-1}\right)$ in the infrared spectra of silica.

\begin{tabular}{lcc}
\hline Aerosil 90 & $\mathrm{SiO}_{2} \mathrm{NP}$ & Assignment \\
\hline 472 & 465 & $\nu_{2} \mathrm{SiO}_{4}$ \\
810.5 & 803 & $\nu(\mathrm{Si}-\mathrm{O}-\mathrm{Si})$ \\
- & 885 & $\nu \mathrm{OH}$ \\
- & 941 & $\nu(\mathrm{Si}-\mathrm{OH})$ \\
\hline
\end{tabular}

Luminescence at $620 \mathrm{~nm}$ in amorphous $\mathrm{SiO}_{2}$ is connected with the trivalent silicon center [33], self-trapped exciton [34], silicon nanoclusters [35, 36], the nonbridging oxygen hole center (NBOHC) [37], quantum confinement effect [38], defects on the $\mathrm{Si} / \mathrm{SiO}_{2}$ [39-41] interface, and so forth. Considering relatively difficult cathodoluminescence spectra given in the real work for unambiguous interpretation of the luminescence centers in the received $\mathrm{NP}^{\mathrm{SiO}}{ }_{2}$, further researches with attraction of additional spectral methods are necessary.

Existence of the three most intensive peaks in red $(618 \mathrm{~nm})$, green $(513 \mathrm{~nm})$, and blue $(451 \mathrm{~nm})$ bands in the spectra of $\mathrm{SiO}_{2}$ NP PCL indicates that the luminescence of NP will have a nearly white color.

\section{Conclusions}

Thus, by means of evaporation by the pulsed electron beam, an amorphous magnetic and luminescent $\mathrm{SiO}_{2} \mathrm{NP}$ is produced which has the following features:

(1) The powder consists of amorphous particles less than $10 \mathrm{~nm}$ in size, the form of particles is far from spheri$\mathrm{cal}$, and the surface of particles is rough. Only Aerosil $380 \mathrm{NP}$ with a high specific surface $\left(380 \mathrm{~m}^{2} / \mathrm{g}\right)$ has 
TABLE 2: The centers of the peaks in the spectrum of pulsed cathodoluminescence $\mathrm{NP} \mathrm{SiO}_{2}$ (Figure 6).

\begin{tabular}{|c|c|c|c|c|}
\hline \multirow{2}{*}{ Peak, number } & \multicolumn{2}{|c|}{ Peak centres } & \multirow{2}{*}{ Association } & \multirow{2}{*}{ References } \\
\hline & $\mathrm{nm}$ & $\mathrm{eV}$ & & \\
\hline \multirow{2}{*}{1} & \multirow{2}{*}{451.5} & \multirow{2}{*}{2.74} & Twofold coordinated silicon centers $\equiv \mathrm{Si}-\mathrm{Si} \equiv$ & {$[30]$} \\
\hline & & & Oxygen-deficient centers & {$[30,42]$} \\
\hline \multirow{2}{*}{2} & \multirow{2}{*}{513} & \multirow{2}{*}{2.4} & Self-trapped exciton & [34] \\
\hline & & & Oxygen vacancy related defect & {$[24]$} \\
\hline \multirow{2}{*}{3} & \multirow{2}{*}{590} & \multirow{2}{*}{2.1} & Nonbridging oxygen hole centers $(\mathrm{NBOHC}) \equiv \mathrm{Si}-\mathrm{O}^{\bullet}$ & [43] \\
\hline & & & Hydrogen-related defects (the $\mathrm{OH}$ group) & {$[24]$} \\
\hline \multirow{5}{*}{4} & \multirow{5}{*}{618} & \multirow{5}{*}{2.00} & $\mathrm{Fe}^{3+}($ transition $(4 \mathrm{G}) \rightarrow(6 \mathrm{~S}))$ & {$[31]$} \\
\hline & & & Si nanocluster & {$[25,35]$} \\
\hline & & & The nonbridging oxygen hole centers $(\mathrm{NBOHC}) \equiv \mathrm{Si}-\mathrm{O}^{\bullet}$ & {$[37,39]$} \\
\hline & & & The quantum confinement effect & {$[38,39]$} \\
\hline & & & Defects in the Si oxide/Si interface & {$[26,39-41]$} \\
\hline 5 & 649 & 1.91 & Nonbridging oxygen hole centers $(\mathrm{NBOHC}) \equiv \mathrm{Si}-\mathrm{O}^{\bullet}$ & {$[24]$} \\
\hline \multirow{2}{*}{6} & \multirow{2}{*}{683} & \multirow{2}{*}{1.81} & $\equiv \mathrm{Si}-\mathrm{O}-\mathrm{O}$ & {$[43]$} \\
\hline & & & Si nanocluster & {$[24,25,36]$} \\
\hline 7 & 702 & 1.76 & Si nanocluster & {$[24,25,30,36]$} \\
\hline 8 & 743 & 1.67 & Si nanocluster & {$[24,25,30,36]$} \\
\hline 9 & 795 & 1.56 & Si nanocluster & {$[25,36]$} \\
\hline
\end{tabular}

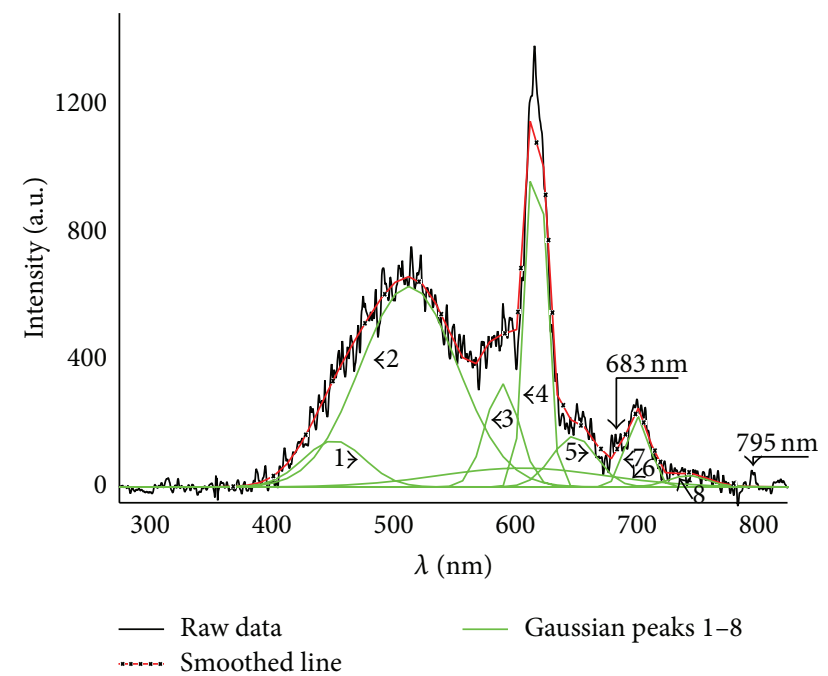

FIgURE 6: Deconvolution into Gaussian components of the PCL spectra of $\mathrm{SiO}_{2} \mathrm{NP}$.

similar particles, of a wrong form and size near about $7 \mathrm{~nm}[18]$.

(2) The powder belongs to soft magnetics and possesses anhysteretic magnetization curve [20, 21] which is peculiar for $\mathrm{d}^{0}$ magnetics; saturation magnetization reaches $0.25 \mathrm{emu} / \mathrm{g}$; coercive force and residual magnetization are close to zero.

(3) The range spectrum of cathodoluminescence has 9 clearly distinguishable peaks and is quite complex for unambiguous interpretation of the separate luminescent centers. Emergence of a narrow, intensive band at $618 \mathrm{~nm}$ can be connected with formation of silicon nanoclusters or with the presence of impurity iron ions or with dependence of intensity of cathodoluminescence on the size of electron beam energy in the KLAVI 1 spectral analyzer.

(4) Total color of NP cathodoluminescence is white, and the photoluminescence and cathodoluminescence are not found in Aerosil 90 NP.

\section{Highlight}

The amorphous nanopowder $\mathrm{SiO}_{2}$ with a specific surface $154 \mathrm{~m}^{2} / \mathrm{g}$ was received by means of evaporation of a target pressed from commercial nanopowder Aerosil 90.

The received nanoparticles of $\mathrm{SiO}_{2}$ have smaller size and more rough surface in comparison with nanoparticles of Aerosil.

The comparative analysis of magnetic, thermal, and optical properties of both nanopowders is carried out.

The undoped $\mathrm{SiO}_{2}$ nanopowder showed ferromagnetic behavior at room temperature.

The nanopowder $\mathrm{SiO}_{2}$ possesses white cathodoluminescence.

\section{Conflict of Interests}

The authors declare that there is no conflict of interests regarding the publication of this paper.

\section{Acknowledgments}

The research is performed with partial support of the projects of the Russian Foundation for Basic Research (nos. 
15-08-01381, 12-03-31593-мол-а, and 13-03-00119-a) and Presidium Ural Branch of the Russian Academy of Sciences and Sverdlovsk Oblast Government (nos. 13-08-96056 P_URAL_a, 12-M-23-2007, and 12-T-3-1009) and Grant ERA.Net RUS Plus-S\&T (NanoRadDos).

\section{References}

[1] G. Kopnov, Z. Vager, and R. Naaman, "New magnetic properties of silicon/silicon oxide interfaces," Advanced Materials, vol. 19, no. 7, pp. 925-928, 2007.

[2] P. J. Grace, M. Venkatesan, J. Alaria, J. M. D. Coey, G. Kopnov, and R. Naaman, "The origin of the magnetism of etched silicon," Advanced Materials, vol. 21, no. 1, pp. 71-74, 2009.

[3] X. Wang, C. Zhen, X. Liu et al., "A new hole-bridge structure based on a $\mathrm{SiO} 2$ nanoarray and its ferromagnetism," Colloids and Surfaces A: Physicochemical and Engineering Aspects, vol. 446, pp. 151-155, 2014.

[4] C. Zhen, Y. Liu, Y. Zhang, L. Ma, C. Pan, and D. Hou, "Roomtemperature ferromagnetism in $\mathrm{Si}-\mathrm{SiO}_{2}$ composite film on glass substrate," Journal of Alloys and Compounds, vol. 503, no. 1, pp. 6-9, 2010

[5] L. T. Canham, "Silicon quantum wire array fabrication by electrochemical and chemical dissolution of wafers," Applied Physics Letters, vol. 57, no. 10, pp. 1046-1048, 1990.

[6] A. G. Cullis, L. T. Canham, and P. D. J. Calcott, "The structural and luminescence properties of porous silicon," Journal of Applied Physics, vol. 82, no. 3, pp. 909-965, 1997.

[7] D. P. Yu, Q. L. Hang, Y. Ding et al., "Amorphous silica nanowires: intensive blue light emitters," Applied Physics Letters, vol. 73, no. 21, pp. 3076-3078, 1998.

[8] A. Colder, F. Huisken, E. Trave et al., "Strong visible photoluminescence from hollow silica nanoparticles," Nanotechnology, vol. 15, no. 3, pp. L1-L4, 2004.

[9] C. Zhao, C. Zhen, Y. Liu et al., "Room-temperature ferromagnetism in silicon oxide/silicon nitride composite films," Solid State Sciences, vol. 14, no. 10, pp. 1454-1457, 2012.

[10] A. Pérez-Rodríguez, O. González-Varona, B. Garrido et al., "White luminescence from $\mathrm{Si}^{+}$and $\mathrm{C}^{+}$ion-implanted $\mathrm{SiO}_{2}$ films," Journal of Applied Physics, vol. 94, no. 1, pp. 254-262, 2003.

[11] M. V. Zamoryanskaya and V. I. Sokolov, "Characterization of $\mathrm{SiO}_{2} / \mathrm{Si}$ interface by cathodoluminescent method," Solid State Phenomena, vol. 131-133, pp. 629-634, 2008.

[12] P. McCord, S.-L. Yau, and A. J. Bard, "Chemiluminescence of anodized and etched silicon: evidence for a luminescent siloxene-like layer on porous silicon," Science, vol. 257, no. 5066, pp. 68-69, 1992.

[13] S. Y. Turishchev, A. S. Lenshin, E. P. Domashevskaya et al., "Evolution of nanoporous silicon phase composition and electron energy structure under natural ageing," Physica Status Solidi (C), vol. 6, no. 7, pp. 1651-1655, 2009.

[14] Y. Y. Bacherikov, S. V. Optasyuk, T. E. Konstantinova, and I. A. Danilenko, "Luminescence from thermally doped nanopowders of zirconia," Technical Physics, vol. 52, no. 6, pp. 747-750, 2007.

[15] S. Y. Sokovnin and V. G. Il'Ves, "Production of nanopowders using pulsed electron beam,” Ferroelectrics, vol. 436, no. 1, pp. 101-107, 2012.
[16] L. Oakes, A. Westover, J. W. Mares et al., "Surface engineered porous silicon for stable, high performance electrochemical supercapacitors," Scientific Reports, vol. 3, article 3020, 2013.

[17] E. Sun, F.-H. Su, Y.-T. Shih et al., "An efficient Si light-emitting diode based on an $\mathrm{n}-\mathrm{ZnO} / \mathrm{SiO}_{2}-\mathrm{Si}$ nanocrystals $-\mathrm{SiO}_{2} / \mathrm{p}-\mathrm{Si}$ heterostructure," Nanotechnology, vol. 20, no. 44, Article ID 445202, 2009.

[18] A. G. Degussa, Basic Characteristics of AEROSIL Fumed Silica, Technical Bulletin Fine Particles no. 11, 4th edition, 2003.

[19] J. R. Martínez, S. Palomares-Sánchez, G. Ortega-Zarzosa, F. Ruiz, and Y. Chumakov, "Rietveld refinement of amorphous $\mathrm{SiO}_{2}$ prepared via sol-gel method," Materials Letters, vol. 60, no. 29-30, pp. 3526-3529, 2006.

[20] J. M. D. Coey, “d ${ }^{0}$ Ferromagnetism," Solid State Sciences, vol. 7, no. 6, pp. 660-667, 2005.

[21] J. M. D. Coey, J. T. Mlack, M. Venkatesan, and P. Stamenov, "Magnetization process in dilute magnetic oxides," IEEE Transactions on Magnetics, vol. 46, no. 6, pp. 2501-2503, 2010.

[22] F. Guan, L. Yao, F. Xie, L. Tian, X. Fang, and S. Pu, "Optical and magnetic properties of $\mathrm{Fe}_{2} \mathrm{O}_{3} / \mathrm{SiO}_{2}$ nano-composite films," Journal Wuhan University of Technology, Materials Science Edition, vol. 25, no. 2, pp. 206-209, 2010.

[23] V. V. Pankov, M. I. Ivanovskaya, and D. A. Kotikov, Collection of Papers: Chemical Problems of Creating New Materials and Technologies, vol. 3 of edited by: O. A. Ivashkevich, Belarusian State University, Minsk, Belarus, 2004.

[24] M. V. Zamoryanskaya, E. V. Ivanova, and A. A. Sitnikova, "Study of the formation of silicon nanoclusters in silicon dioxide during electron beam irradiation," Physics of the Solid State, vol. 53, no. 7, pp. 1474-1480, 2011.

[25] R. Salh, "Silicon nanocluster in silicon dioxide: cathodoluminescence, energy dispersive X-ray analysis and infrared spectroscopy studies," in Crystalline Silicon-Properties and Uses, S. Basu, Ed., chapter 9, InTech, Rijeka, Croatia, 2011.

[26] E. V. Ivanova and M. V. Zamoryanskaya, "Investigation of point defects modification in silicon dioxide by cathodoluminescence," Solid State Phenomena, vol. 205-206, pp. 457-461, 2014.

[27] V. N. Bogomolov, S. A. Gurevich, M. V. Zamoryanskaya, A. A. Sitnikova, I. P. Smirnova, and V. I. Sokolov, "Silicon nanocluster formation under electron-beam-induced modification of a silicate matrix," Physics of the Solid State, vol. 43, no. 2, pp. 373376, 2001.

[28] L. A. Bakaleǐnikov, M. V. Zamoryanskaya, E. V. Kolesnikova, V. I. Sokolov, and E. Y. Flegontova, "Silicon dioxide modification by an electron beam," Physics of the Solid State, vol. 46, no. 6, pp. 1018-1023, 2004.

[29] E. V. Kolesnikova and M. V. Zamoryanskaya, "Silicon nanoclusters formation in silicon dioxide by high power density electron beam," Physica B: Condensed Matter, vol. 404, no. 23-24, pp. 4653-4656, 2009.

[30] A. Leto, M. C. Munisso, A. A. Porporati, W. Zhu, and G. Pezzotti, "Stress dependence of paramagnetic point defects in amorphous silicon oxide," Journal of Physical Chemistry A, vol. 112, no. 17, pp. 3927-3934, 2008.

[31] H. B. Premkumar, H. Nagabhushana, S. C. Sharma et al., "Synthesis, EPR and luminescent properties of $\mathrm{YAlO}_{3}: \mathrm{Fe}^{3+}(0.1-$ 0.9 mol\%) nanopowders," Spectrochimica Acta A: Molecular and Biomolecular Spectroscopy, vol. 126, pp. 220-226, 2014.

[32] O. M. Zhilicheva, On luminescent properties of minerals in this pulsed cathodoluminescence [The Thesis for the Degree of Candidate of Geological and Mineralogical Sciences], 2010 (Russian). 
[33] M. H. Ludwig, J. Menniger, and R. E. Hummel, "Cathodoluminescing properties of spark-processed silicon," Journal of Physics: Condensed Matter, vol. 7, no. 47, pp. 9081-9089, 1995.

[34] C. Itoh, T. Suzuki, and N. Itoh, "Luminescence and defect formation in undensified and densified amorphous $\mathrm{SiO}_{2}$," Physical Review B, vol. 41, no. 6, pp. 3794-3799, 1990.

[35] G. Ledoux, J. Gong, and F. Huisken, "Effect of passivation and aging on the photoluminescence of silicon nanocrystals," Applied Physics Letters, vol. 79, no. 24, pp. 4028-4030, 2001.

[36] G. D. Sanders and Y.-C. Chang, "Theory of optical properties of quantum wires in porous silicon," Physical Review B, vol. 45, no. 16, pp. 9202-9213, 1992.

[37] T. Suzuki, L. Skuja, K. Kajihara, M. Hirano, T. Kamiya, and $\mathrm{H}$. Hosono, "Electronic structure of oxygen dangling bond in glassy $\mathrm{SiO}_{2}$ : the role of hyperconjugation," Physical Review Letters, vol. 90, no. 18, Article ID 186404, 2003.

[38] B. Delley and E. F. Steigmeier, "Size dependence of band gaps in silicon nanostructures," Applied Physics Letters, vol. 67, no. 16, pp. 2370-2372, 1995.

[39] G. Jia, T. Arguirov, M. Kittler, Z. Su, D. Yang, and J. Sha, "Cathodoluminescence investigation of silicon nanowires fabricated by thermal evaporation of SiO," Semiconductors, vol. 41, no. 4, pp. 391-394, 2007.

[40] X. H. Sun, N. B. Wong, C. P. Li, S. T. Lee, and T. K. Sham, "Chainlike silicon nanowires: morphology, electronic structure and luminescence studies," Journal of Applied Physics, vol. 96, no. 6, pp. 3447-3451, 2004.

[41] D. D. D. Ma, S. T. Lee, and J. Shinar, "Strong polarizationdependent photoluminescence from silicon nanowire fibers," Applied Physics Letters, vol. 87, no. 3, Article ID 033107, 2005.

[42] A. F. Zatsepin, "Statics and dynamics of excited states of oxygendeficient centers in $\mathrm{SiO}_{2}$," Physics of the Solid State, vol. 52, no. 6, pp. 1176-1187, 2010.

[43] L. Skuja, "Optically active oxygen-deficiency-related centers in amorphous silicon dioxide," Journal of Non-Crystalline Solids, vol. 239, no. 1-3, pp. 16-48, 1998. 

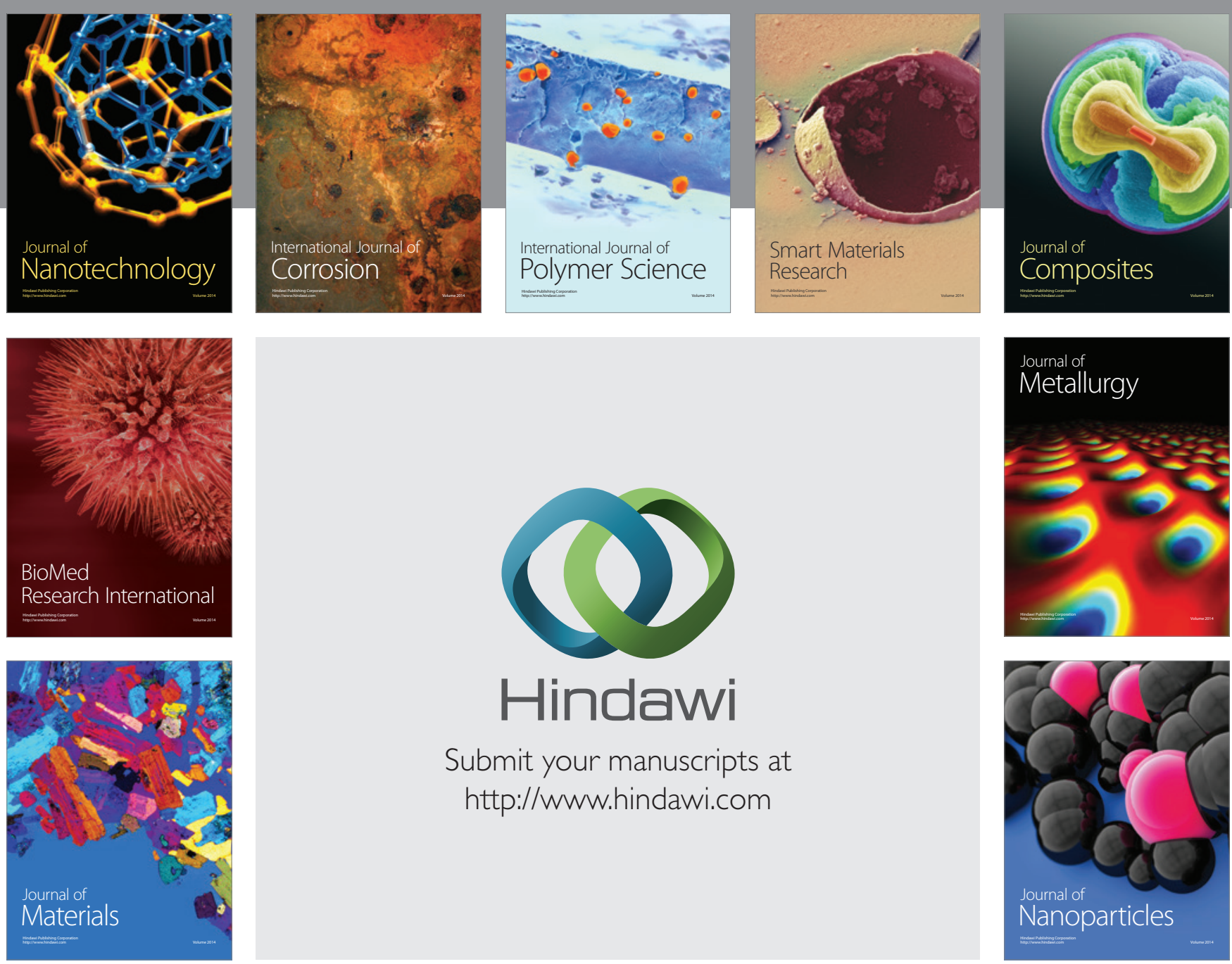

Submit your manuscripts at http://www.hindawi.com
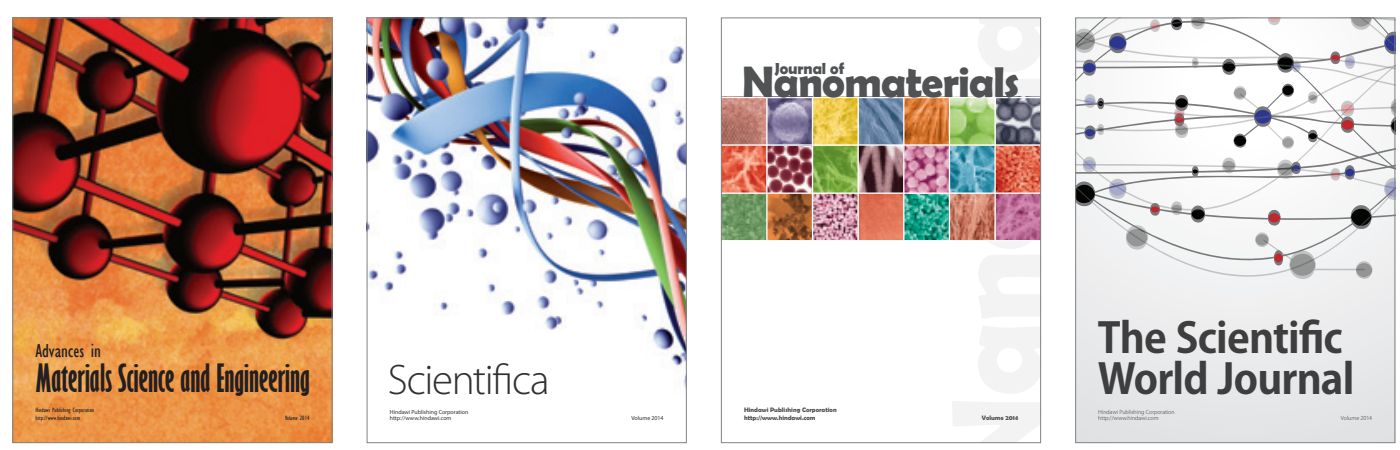

\section{The Scientific World Journal}
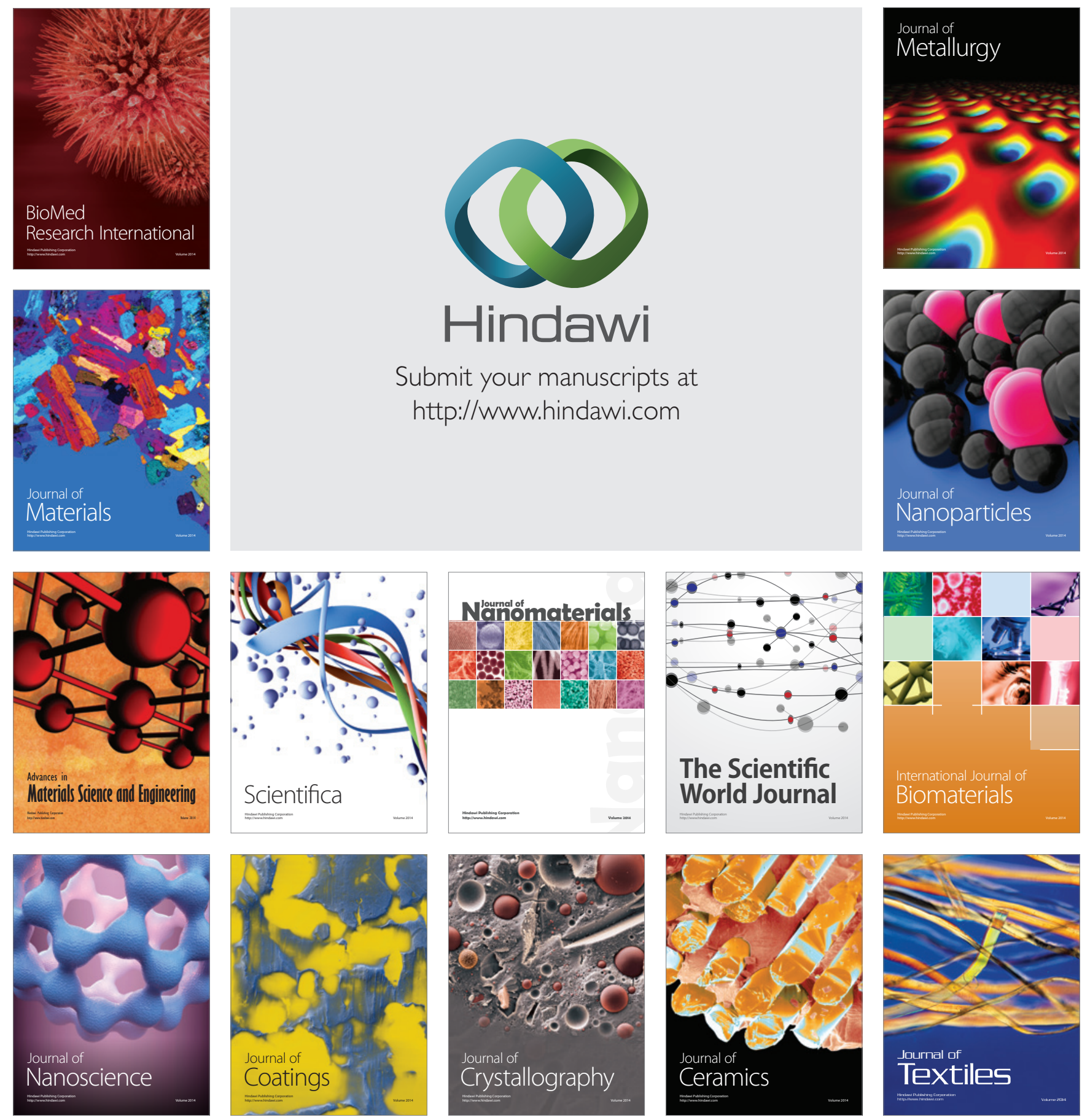